\title{
Therapeutic efficiency of adipose-derived mesenchymal stem cells in healing of experimentally induced gastric ulcers in rats
}

\author{
Safaa A. Hassan ${ }^{1}$, Amal Taha Abou Elghait ${ }^{1,2}$, Zainab S. Abdelqader ${ }^{1}$, Fatma Y. Meligy ${ }^{1}$ \\ ${ }^{1}$ Histology and Cell Biology Department, Faculty of Medicine, Assiut University, Assiut, ${ }^{2}$ Histology and Cell Biology Department, Sphinx University, \\ Assiut, Egypt
}

\begin{abstract}
Gastric (peptic) ulcer is a major gastrointestinal disorder with high morbidity and mortality. While several drugs have been used to treat gastric ulcers, such as proton pump inhibitor-based triple therapy for Helicobacter pylori eradication, but hey result in adverse side effects. Therefore, development of new alternative therapies is desirable. Many recent studies have shown that mesenchymal stem cells (MSCs) might have an enhancing effect on the ulcerated gastric mucosa. The aim of this study is to evaluate the efficacy of MSCs in the treatment of indomethacin-induced gastric ulcer, and to compare it with the normal ulcer autohealing. This work was performed on 36 adult male albino rats, divided into four groups: Group I (control group), Group II (ulcer group), Group III (autohealing group), and Group IV (stem cells-treated group). The histological changes of gastric mucosa were examined in sections stained with $\mathrm{H} \& \mathrm{E}$ using light microscope for expression of vascular endothelial growth factors (VEGF) and proliferating cell nuclear antigen (PCNA) in immunohistochemical stained sections using image analyzer. The results from MSCs-treated group revealed restoration of the normal architecture of the gastric mucosa with comparison to the autohealing group which showed excessive granulation tissue and heavy cellular infiltration with disorganized architecture of the fundic mucosa. Immunohistochemical examination showed strong expression of both VEGF and PCNA in the MSCs-treated group. So it was concluded that MSCs accelerate gastric ulcer healing when injected intraperitoneally, compared to autohealing process which showed delayed healing.
\end{abstract}

Key words: Gastric ulcer, Mesenchymal stem cells, Indomethacin, Proliferating cell nuclear antigen, Vascular endothelial growth factors

Received February 18, 2021; 1st Revised April 24, 2021; 2nd Revised May 31, 2021; Accepted June 1, 2021

\section{Introduction}

Gastric (peptic) ulcer is a major gastrointestinal disorder with high morbidity and mortality [1]. It occurs due to an imbalance among aggressive factors (such as acid-pepsin

\section{Corresponding author:}

Fatma Y. Meligy (iD

Histology and Cell Biology Department, Faculty of Medicine, Assiut University, Assiut 71415, Egypt

E-mail: fmeligy@aun.edu.eg secretion), mucosal protection factors (like mucus and bicarbonate secretion), and the process of regeneration after cellular injury [2].

The most common causes of gastric ulcer are the use of non-steroidal anti-inflammatory drugs (NSAIDs), and tobacco smoking [3]. Gastric ulcers occur in $4 \%$ of the population mostly in elderly [4].

Individuals with gastric ulcer are at risk of developing complications such as gastric hemorrhage, perforation, and obstruction [5]. Globally about 15 patient among every 15,000 die each year from gastric ulcer complications $[6,7]$. Several drugs have been used to treat gastric ulcer; how-

\section{Copyright ( 2021 . Anatomy \& Cell Biology}

This is an Open Access article distributed under the terms of the Creative Commons Attribution Non-Commercial License (http://creativecommons.org/licenses/by-nc/4.0/) which permits unrestricted non-commercial use, distribution, and reproduction in any medium, provided the original work is properly cited. 
ever, the literature contains many reports of the association between long-term use of proton pump inhibitors and the adverse side effects such as bacterial overgrowth within the gastric mucosa and community acquired pneumonia [3]. Providing gastric protection by preventing NSAID-induced peptic ulcer disease is still considered a difficult issue $[1,8]$.

Gastric mucosal defense mechanisms include local defense mechanisms by the mucus bicarbonate barrier [9], and surface epithelial cells [10]. Another local defense mechanism is continuous cell renewal by mucosal progenitor cells to replace injured or aged surface epithelial cells completely within 3 to 7 days; and in glandular cells, it takes months [11]. Additional local defense mechanisms include alkaline tide, mucosal microcirculation [12], and continuous generation of prostaglandin $\mathrm{E}_{2}$ (PGE2) and prostaglandin $\mathrm{I}_{2}$ (PGI2) by the mucosa [13]. Neurohormonal regulation of the gastric mucosal defense is another important line of defense in which central corticotropin-releasing factor signaling pathways contribute to the endocrine and visceral responses to stress [14].

Gastric ulcers result from tissue sloughing initiated by mucosal ischemia, free radical formation and hindered nutrient access. They are caused by vascular and microvascular injury such as thrombi, constriction, or other occlusions [15].

Ulcer healing is an active and complicated process that involves re-epithelialization, granulation tissue formation, and angiogenesis. It requires the interaction of a variety of tissues and cellular systems as well as a number of growth factors as vascular endothelial growth factor (VEGF) and cytokines [16].

Mesenchymal stem cells (MSCs) are undifferentiated multipotent cells which are able to proliferate, self-renew, and differentiate into multiple cell lineages $[17,18]$. Because of their unique capabilities as immunomodulatory, multipotent and fast proliferating cells, MSCs can be used for a wide range of treatments [3]. A cascade of events occurs when MSCs enter the microenvironment of injured tissues. Many factors including toxins of infectious agents, inflammatory stimuli, hypoxia and cytokines such as TNF- $\alpha$, interleukin (IL)-1, interferon- $\gamma$; stimulate MSCs to release many growth factors, such as EGF, FGF, PDGF, TGF-b, VEGF, HGF, insulin growth factor-1, angiopoietin-1, keratinocyte growth factor, and stromal cell derived factor-1 [19]. These growth factors enhance the development of fibroblasts, endothelial cells and tissue progenitor cells, which implement tissue replacement and repair [20]. It has been reported that trophic factors produced by MSCs can be used to achieve therapeutic effects to inflammatory diseases, whereas in damaged tissue engrafted MSCs can act in harmony with immune cells, stromal cells, endothelial cells and tissue progenitor cells to enhance tissue repair $[21,22]$.

In our study, we examined the role of MSCs in treatment of the gastric ulcer.

\section{Materials and Methods}

\section{Experimental animals}

A total number of 36 male albino rats (aged 8 weeks, weighing 150-200 g) were purchased from the Animal House of Assiut University. The animals were maintained under controlled laboratory conditions for humidity, temperature, and light /dark cycle and fed normal rat' chow and allowed free access to water. All animal procedures used were approved by the Institutional Ethics Committee of Assiut University (17200549).

\section{Drugs and chemicals}

Indomethacin ampules (EL-NILE Company, Cairo, Egypt). VEGF antibody (Cat. NO NBP2-45235; Novus Biologicals, Centennial, CO, USA) and Proliferating cell nuclear antigen antibody (PCNA; Cat log \#YPA1100; Biospes, Chongqing, China).

\section{Isolation and culture of mesenchymal stem cells}

Adipose tissue specimens from lipectomy procedures were obtained aseptically from the Plastic Surgery Department, Assiut University Hospital. The tissues were dissected into very small pieces; digested using collagenase solution, and transferred to a shaking water bath where they were incubated at $37^{\circ} \mathrm{C}$ for 1 hour. The solution was centrifuged and washed, sieved through nylon mesh, and cultured in complete media. On the second day, the cultured cells were examined using an inverted microscope. The cells underwent two passages before transplantation into the rats [23].

\section{Experimental design}

The animals were divided into 4 main groups. Group I, group II, group III , and Group IV. Group III and IV are divided into two subgroups. Each main and sub group contains 6 rats.

Group I (control group): the rats received isotonic saline. Group II (ulcer group): the rats fasted for 24 hours, with free 
water intake, and then were given indomethacin $200 \mathrm{mg} / \mathrm{kg}$ orally [24]. After 4 hours, they were sacrificed [25]. Group III (autohealing groups) subdivided into Group IIIa and Group IIIb). Group IIIa: after ulcer induction, the rats were left to heal spontaneously without any intervention, they were dissected after the 1st day. Group IIIb: after ulcer induction, the rats were left to heal spontaneously without any intervention except for isotonic saline injection then dissected after the 4th day. Group IV (stem cells-treated groups) subdivided into Group IVa and Group IVb. Group IVa: after ulcer induction the rats were injected intraperitoneally with a single dose of MSCs $\left(1 \times 10^{6}\right.$ cell) [26]. They were dissected after the 1 st day. Group IVb: after ulcer induction the rats were injected intraperitoneally [27], with a single dose of MSCs $\left(1 \times 10^{6}\right.$ cell) and were dissected after the 4th day. Normal animals received MSCs in a single dose $\left(1 \times 10^{6}\right.$ cell $)$ cells. After scarification and dissection after the 1 st and 4 th days, the stomachs were subjected to RNA extraction and subsequent steps taken to detect human leukocyte antigen (HLA) in the specimens.

\section{Macroscopic examination}

At the end of the experiment, the dissected stomachs were photographed using the dissecting microscope at the Histology Department to document the number and size of the ulcers and allow calculation of the ulcer index for the different groups. Ulcer index: The ulcer severity can be evaluated according to the scale using a modification of the score created by Kunchandy et al. [28] as follows: 0, Normal gray colored stomach; 0.5 , Pink to red coloration of stomach; 1 , Spot ulcer; 1.5, Hemorrhagic streak; 2, Number of ulcers less than 5 ; 3 , Number of ulcer more than or equal to $5 ; 4$, Ulcer with bleeding and 5; Perforation of gastric/duodenal wall. The ulcer index was calculated by adding the total number of ulcers plus the severity of each ulcer.

\section{Light microscopic examination}

\section{By hematoxylin and eosin stain}

Stomach sections from the six groups were fixed in $10 \%$ formalin, embedded in paraffin, cut into sections, $5 \mu \mathrm{m}$ thick, and stained with Hematoxylin \& Eosin (H\&E) to assess the extent of injury (gastric ulcer) and detect evidence for the extent of healing [29].

\section{Immunohistochemical preparation for VEGF and PCNA antibodies}

Paraffin embedded sections were used for immunostaining. Briefly, hydrogen peroxidase was added to the sections for 10 minutes. Antigen retrieval was done by adding citrate buffer to the slides which were placed in a microwave for 9 minutes. Primary antibodies were added (1:200; VEGF), (1:100; PCNA) for the Group 1, 2, IIIa, IIIb, IVa, and IVb. The slides were incubated with antibodies at $4^{\circ} \mathrm{C}$ over night, followed by secondary antibody (Asnf Medical Company, Cairo, Egypt) for 15 minutes. DAB buffer was mixed with chromogen and added to the slides for 10 minutes. Slides were stained by H\&E stain [30], mounted, covered and examined by light microscope.

\section{Flow cytometry analysis for mesenchymal stem cells}

Isolated adipose derived MSCs were analyzed using a fluorescence-activated cell sorting (FACS) cell analyzer at Southern Egypt Institute of Tumors, Assiut University [31]. The cells were harvested and incubated for 30 minutes on ice with $1 \%$ bovine serum albumin containing the primary antibodies directed against: CD90, CD45, CD73, CD271, and CD34 (Santa Cruz Biotechnology, Santa Cruz, CA, USA), after which the cells were washed and incubated for another 30 minutes away on ice from light with Alexa Fluor 647 (Santa Cruz Biotechnology). The cells were washed again.

\section{Gene expression of HLA in control \& stem cells treated groups}

RNA extraction was carried out from stomach of MSCs injected groups (Group I and IV) on the 1st and 4th days using an RNase extraction kit according to manufacturer's directions. All polymerase chain reaction (PCR) reagents were obtained from Applied Biosystems (Waltham, MA, USA) and examined using RT2SYBR ${ }^{\circledR}$ (Precision PLUS Master Mix premixed with SYBR green). Complementary DNA (cDNA) was synthesized from RNA using reverse transcriptase with random primers. The reaction mixture was then subjected to PCR amplification with specific forward and reverse oligonucleotide primers for 40 cycles. The samples were run on $1 \%$ agarose gel and photographed under UV light. Regarding qRT-PCR for quantitative expression of HLA; an aliquot of 1,000 ng of the total RNA from the sample was used for complementary cDNA synthesis by reverse transcription using a high capacity CDNA Reverse Transcriptase kit (CAT \#4368814; Applied Biosystems). The cDNA was 
subsequently amplified with the SYBR Green I PCR Master Kit (CAT \#K0251; Fermentas, Waltham, MA, USA) using the Step One instrument (Applied Biosystems), and the Precision PLUS Master Mix premixed with SYBR green. Samples were prepared for reverse transcription with the precision Nano Script 2 Reverse Transcription kit. The reactions were done using a thermal cycler (MJ Research, Inc., Waltham, MA, USA). The thermal profile consisted of 2 minutes at $50^{\circ} \mathrm{C}, 10$ minutes at $95^{\circ} \mathrm{C}$, followed by 40 cycles of 15 seconds at $95^{\circ} \mathrm{C}$, and 1 minute at $60^{\circ} \mathrm{C}$. Gene expression was normalized with the house keeping gene (GADPH) and reported as fold change in expressions. Primers used were as follows: HLA-DQB-10201: Forward primer GTGCGTCT TGTGAGCAGAAG, Reverse primer: GCAAGGT CGT GCGGAGCT (Size 205 bp). Glyceraldehyde 3 phosphatedehydrogenase (GAPDH)F: AAC TTT GGC ATT GTG GAA GG R: ACA CAT TGG GGG TAG GAA CA [32].

\section{Morphometric studies}

The numbers of ulcers were calculated grossly in all groups to assess the ulcer index.

Computerized image analyzer system software (Leica Q 500 MCO; Leica, Wetzlar, Germany) connected to a camera attached to a Leica universal microscope at the Histology Department, Faculty of Medicine, Assiut University was used. Six non overlapping fields in 5 randomly chosen PCNA immunostained sections from three different rats from Groups I, II, IIIa, IIIb, IVa, and IVb were used.

\section{Statistical analysis}

Statistical analysis was performed using the GraphPad Prism $^{\circledR}$ software package, version 7 (GraphPad Prism 7 Software Inc., San Diego, CA, USA). Analysis of variance (ANOVA) followed by Tukey-Kramer multiple comparisons test was done for ulcer index and PCNA while unpaired Student's $t$-test was used for statistical analysis of HLA expression. Data were considered significant at $P<0.05$. Data were expressed as mean \pm standard error of mean.

\section{Results}

\section{The macroscopic examination}

The opened dissected stomachs of rats from Group I showed that the mucosa of stomach the near esophagus (fore stomach) is whitish in color and the mucosa near the small intestine (glandular stomach) is greyish pink in color with prominent rugae (Fig. 1A). In Group II, The glandular stomachs showed multiple a dark brown mucosal lesion of different sizes, shapes and number (ranged from 8 to 9 with mean of 8.0) (Fig. 1B). The glandular stomachs of Group IIIa revealed multiple dark brown lesions (range, 5-7; mean, 7.75) (Fig. 1C). In Group IIIb, the glandular stomachs showed a few dark brown lesions (range, 1-2; mean, 3.5) (Fig. 1D). As regard of Group IVa, the glandular stomachs showed fewer lesions (range, 2-3; mean, 3.5) than were observed on the 1st day in Group III (Fig. 1E). While in Group IVb, The glandular stomachs showed very small dark brown lesions (mean, 0.875 ) which was decreased compared with observation with the Group III on the 4th day (Fig. 1F). Significant difference from the Group I at $P<0.05$, significant difference from the Group II at $P<0.05$; histogram 1 (Fig. 1G).

\section{Hematoxylin and eosin stain}

The sections of the glandular stomach of Group I showed that the fundic mucosa has normal intact surface epithelium with gastric pits. The surface epithelium and gastric pits are lined with simple columnar epithelial cells containing oval nuclei and pale vacuolated acidophilic cytoplasm (Fig. 2B). Fundic glands with regular narrow tubules occupying the whole thickness of the lamina propria were observed. They comprised an isthmus, neck, and base. In addition, the muscularis mucosa, submucosa and muscularis externa all presented a normal appearance (Fig. 2A). The lamina propria contained connective tissue (C.T.) cells and fibers (Fig. 2B). The fundic glands are lined by mucous neck cells, parietal cells and chief cells. The mucous neck cells occupied the upper portion of the glands (the neck) and were lodged in between the parietal cells (Fig. 2B). They were columnar cells with pale basophilic cytoplasm and oval nuclei. The parietal cells occupied the middle and lower part of the glands. They were rounded or pyramidal in shape with rounded nuclei and deep acidophilic cytoplasm (Fig. 2B, C). The chief cells predominated in the lower part of the glands and were columnar in shape with rounded nuclei and cytoplasm showed basal basophilia and apical acidophilia. The muscularis mucosa appeared to comprise two layers of smooth muscle cells; inner circular and outer longitudinal cells with flat nuclei and acidophilic cytoplasm (Fig. 2C). The submucosa appeared to be composed of C.T. and blood capillaries (Fig. 2C). In Group II, the H\&E stained sections showed variable degrees of mucosal lesions comprising partial loss of the mucosa, shedding of the whole thickness of the epithelium 

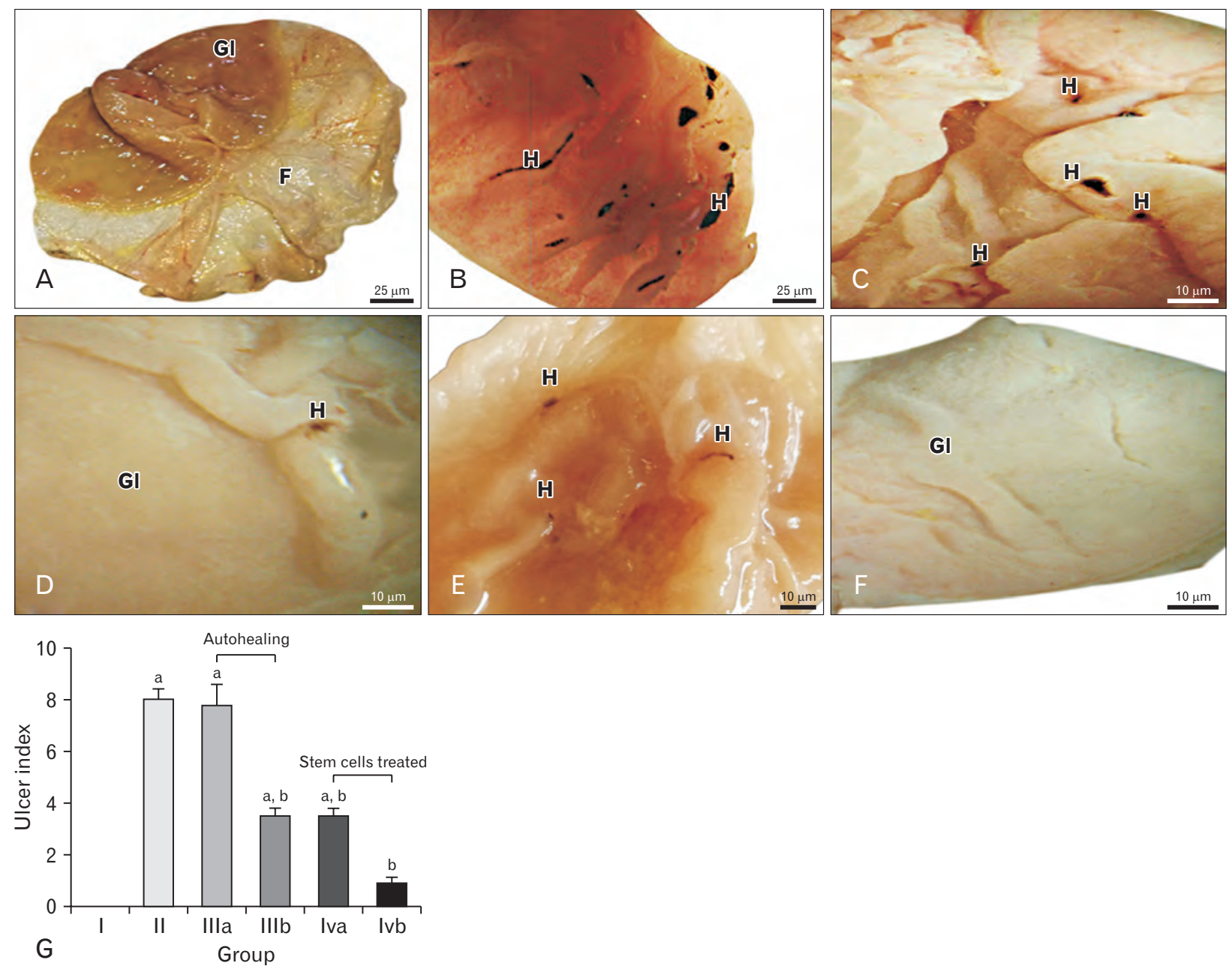

Fig. 1. Macroscopic photographs of gastric mucosa from rats in the six groups showing: (A) the glandular portion (Gl) with stomach rugae and fore-stomach (F) (Group I). (B-E) Showing numerous hemorrhagic lesions in the glandular mucosa (H) (Group II); (C) Group IIIa; (D) Group IIIa; (E) Group IVa; (F) Group IVb. (G) Stastical analysis of the ulcer index. ${ }^{2}$ Significant difference from the control group (Group I) at $P<0.05$; ${ }^{\mathrm{b}}$ Significant difference from the ulcer group (Group II) at $P<0.05$.

and disorganized fundic glandular cells with preservation of some glands (as the chief cells) in the lower portion of the mucosa (Fig. 2A, B). The surrounding fundic mucosa showed normal structure (Fig. 2A). Dilated blood capillaries were detected in the lamina propria (Fig. 2A, C). Widening of spaces of the submucosal C.T. components was also observed (Fig. 2A). Some of the surface epithelial cells showed densely stained nuclei with distorted cell shape (Fig. 2B). The glandular cells were also distorted in shape and arrangement and their nuclei were densly stained (Fig. 2B). The parietal cells lost their normal arrangement and appeared vacuolated and ballooned. Some of the parietal cells demonstrated deeply acidophilic cytoplasm and densly stained nuclei, while others preserved their normal histological structure (Fig. 2B, C).
Mononuclear cellular infilteration appeared in the lamina propria(Fig. 2C). The H\&E stained sections of glandular stomach mucosa of Group IIIa showed minimal regeneration features (Fig. 2A). Partial loss of fundic mucosa and invasion of the ulcer with granulation tissue (fibroblasts and blood capillaries) were detected (Fig. 2A). The architecture of the mucosa remained disorganized with poorly differentiated fundic glands (Fig. 2C). Monocellular infiltration was detected in both the lamina propria (Fig. 2B, C). The H\&E stained sections of Group IIIb revealed disorganized epithelial and glandular cells (Fig. 2). In addition, heavy cellular infilteration of lamina propria and submucosa with granulation tissue was detected (Figs. 2A, B). Lymphocytic infilteration was observed (Fig. 2B). Infrequent parietal cells appeared 


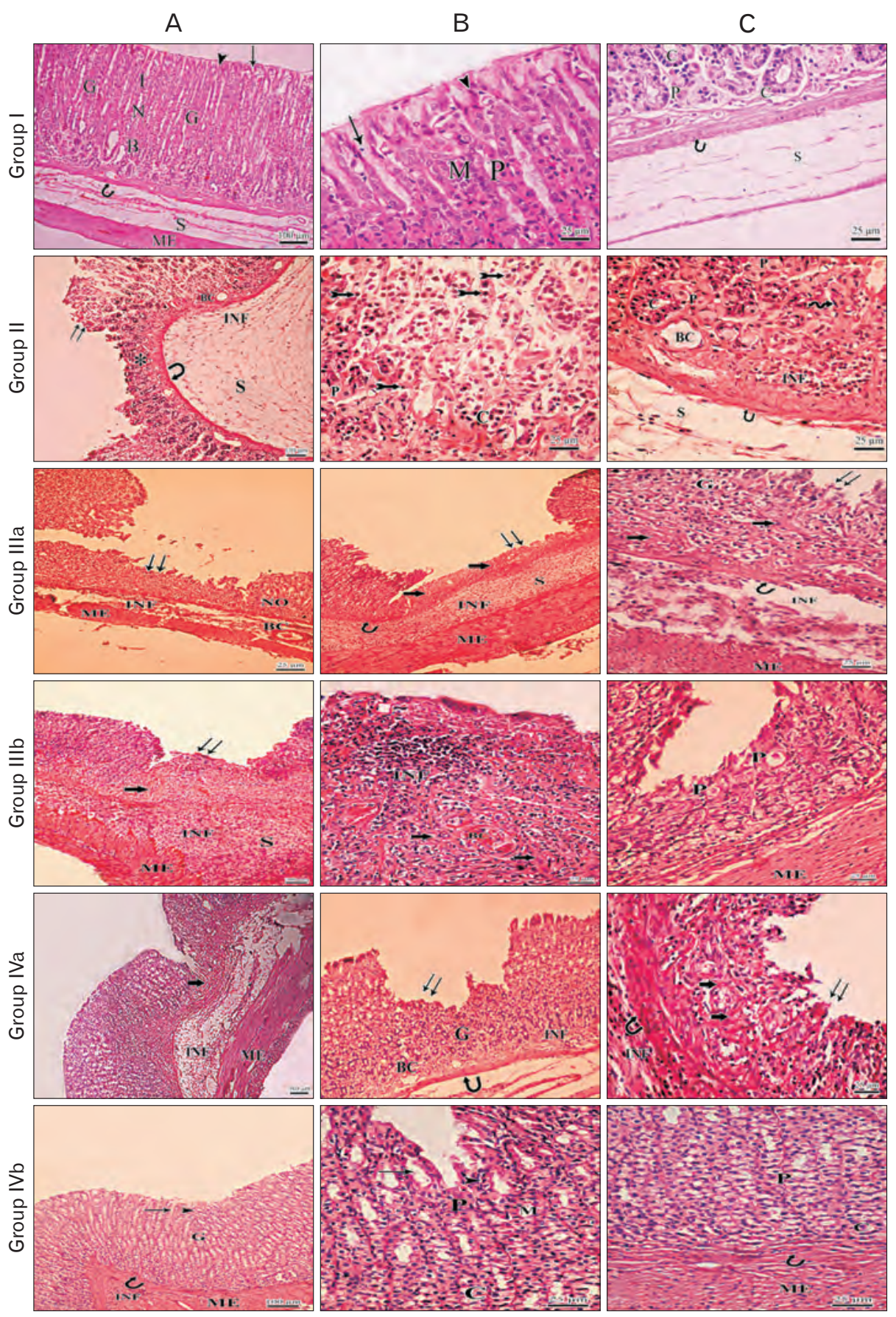

Fig. 2. H\&E stained sections of the glandular portion showing (Group I) surface epithelium (arrowhead) and gastric pits (arrow) (A), high magnification (B, C). Group II (A) the ulcer region (double arrow) with with disfigured appearance and partial shedding of the surface epithelium (E) and upper portion of the gland and NO. (B, C) High magnification; the middle and lower part of fundic glands showing dense pyknotic nuclei (tailed arrow), cellular infilteration (INF), and nuclei of connective tissue (CT) cells (wavy arrow). Group IIIa (A, B) the glandular portion showing partial loss of the mucosa in the ulcer region (double arrow) with apparent normal mucosa (NO), cellular infilteration of the submucosa (INF) and dilated blood capillaries (BC), Disorganized fundic glands (G) with granulation tissue (thick arrow), high magnification (C). Group IIIb (A) the fundic mucosa in the ulcer region (double arrow), granulation tissue (thick arrow) with disfigured epithelial and glandular cells and heavy cellular infilteration (INF) of mucosa and submucosa (S), (B, C) high magnification shows infrequent parietal cells (P). Group IVa (A, B) fundic mucosa in the ulcer region (double arrow) with disorganized mucosa, granulation tissue (thick arrow) and cellular infiltration (INF) of submucosa. (C) High magnification. Group IVb (A) the glandular parts showing complete restoration of the epithelium (arrow head), gastric pits (arrow) and fundic glands $(\mathrm{G})$, the muscularis mucosa (curved arrow) and muscularis externa (ME) appear normal. (B, C) Parietal (P) cells, mucous neck (M) cells and chief cells (C) appear normal, the parietal cells (P) and chief cells (C) appear normal. Scale bar for all photomicrographs: $25 \mu \mathrm{m}$. 


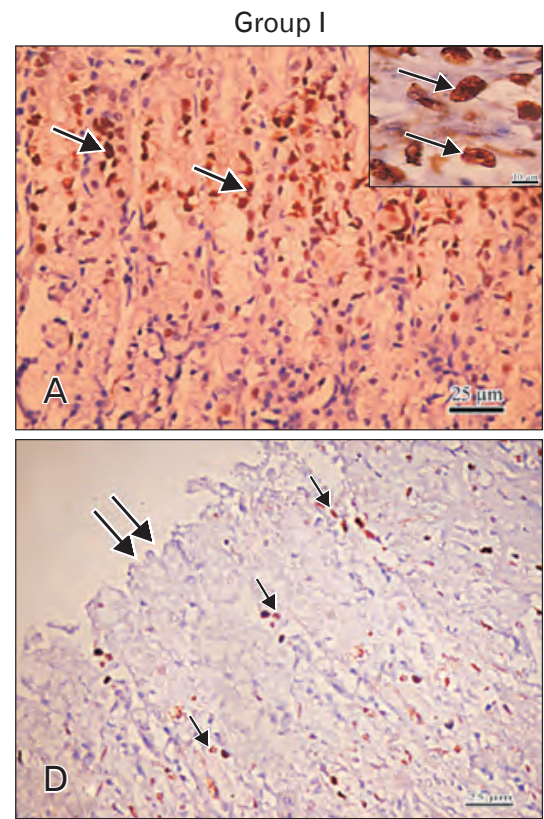

Group IIIb
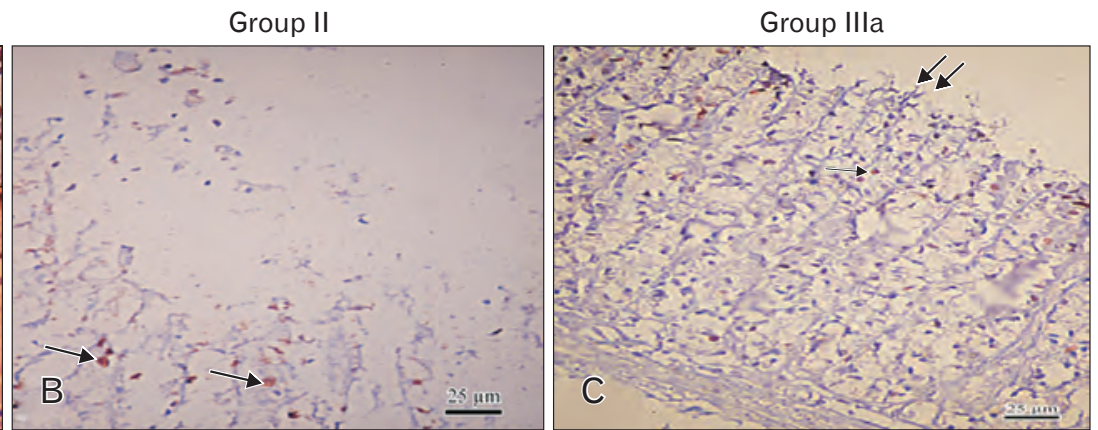

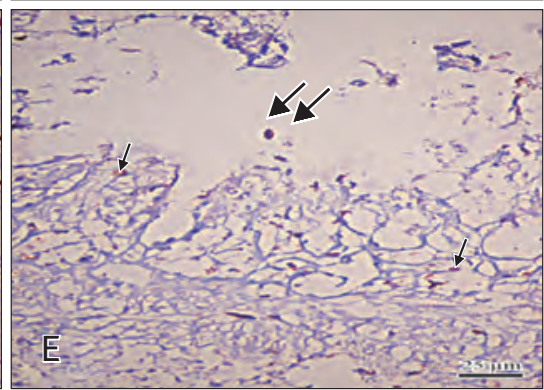

Group IVa

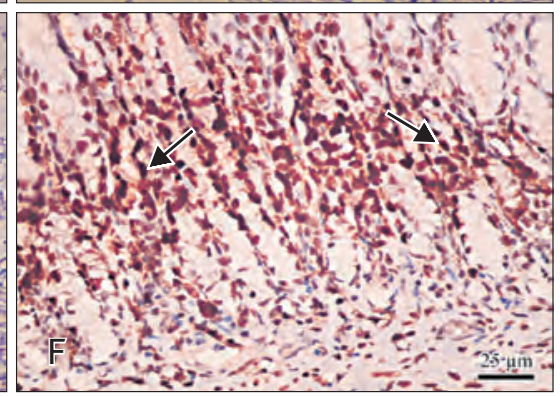

Group IVb

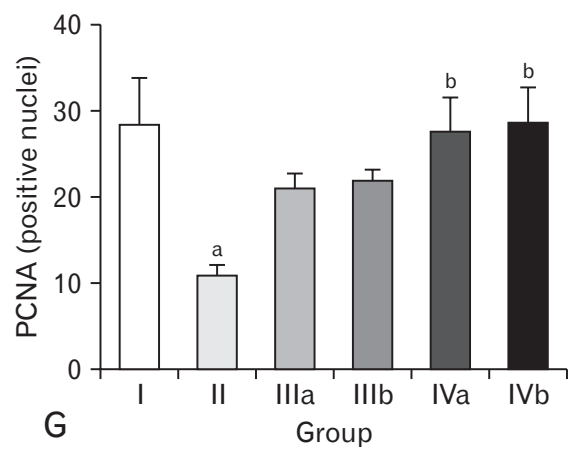

Fig. 3. Immunostained section for proliferating cell nuclear antigen (PCNA) shows Group I (A), the expression in the epithelium (arrows), inset; Group II (B), weak PCNA antibody expression (arrows) in the ulcer region; Group IIIa (C), weak PCNA antibody expression (arrow) in the ulcer region (double arrow); Group IIIb (D), weak PCNA antibody expression (arrows) in ulcer region (double arrow); Group IVa (E), weak PCNA antibody expression (arrow) in the ulcer region (double arrow); Group IVb (F), strong PCNA expression (arrows) at the neck region. (G) Statistical analysis. ${ }^{a}$ Significant difference from the control group (Group I) at $P<0.05$. 'Significant difference from the ulcer group (Group II) at $P<0.05$. Scale bar for all photomicrographs: $25 \mu \mathrm{m}$.

ballooned with vacuolated cytoplasm and irregular dense nuclei. The other types of glandular cells were difficulty distiguished (Fig. 2C). Dilated blood capillaries were detected (Fig. 2B). In Group IVa, the H\&E stained sections of glndular mucosa showed healed areas composed of granulation tissue. There were some fundic glandular cells that had begun to regenerate but the glandular architecture was still not well organized. In addition, there was heavy cellular infiltration (neutrophils, monocytes and lymphocytes) of the lamina propria (Fig. 2). The sections of glandular mucosa of Group IVb showed that was complete restoration of the epithelium and fundic glands (parietal, mucous neck and chief cells) with minimal cellular infiltration and granulation tissue (Fig. 2).

\section{Immunohistochemical results}

\section{Proliferating cell nuclear antigen}

The immunostained sections of Group I showed characteristic expression of PCNA in the epithelium, more apparent in the neck region, in the form of dark brown colored nuclei (Fig. 3A). In Group II, the immune-stained sections showed weak expression of PCNA in the ulcer region (Fig. 3B). In Group IIIa, The immune-stained sections showed weak 


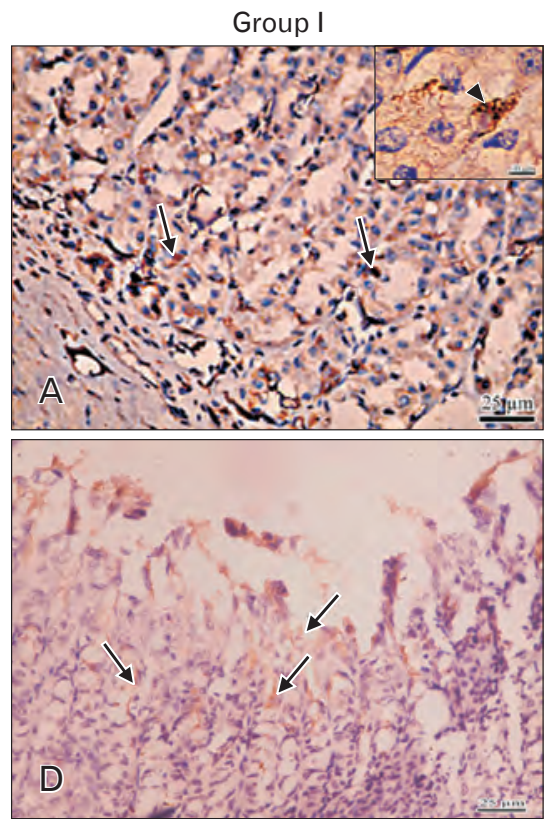

Group IIIb

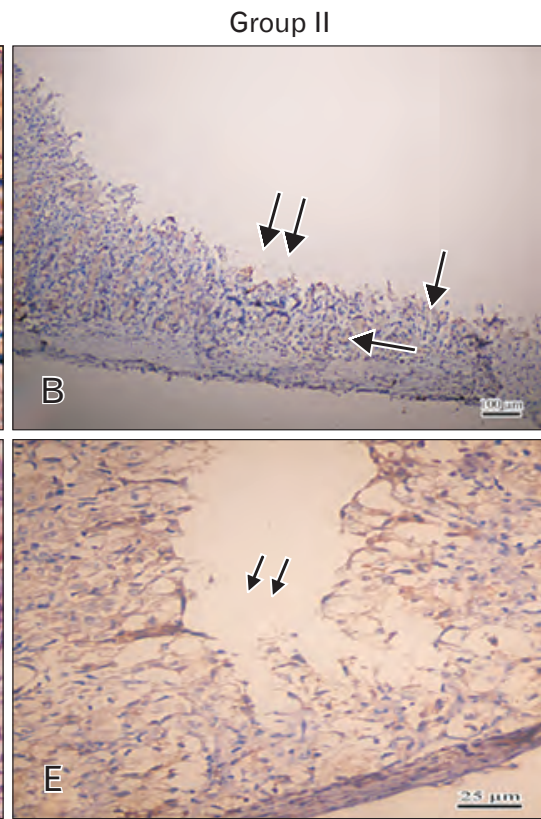

Group IVa

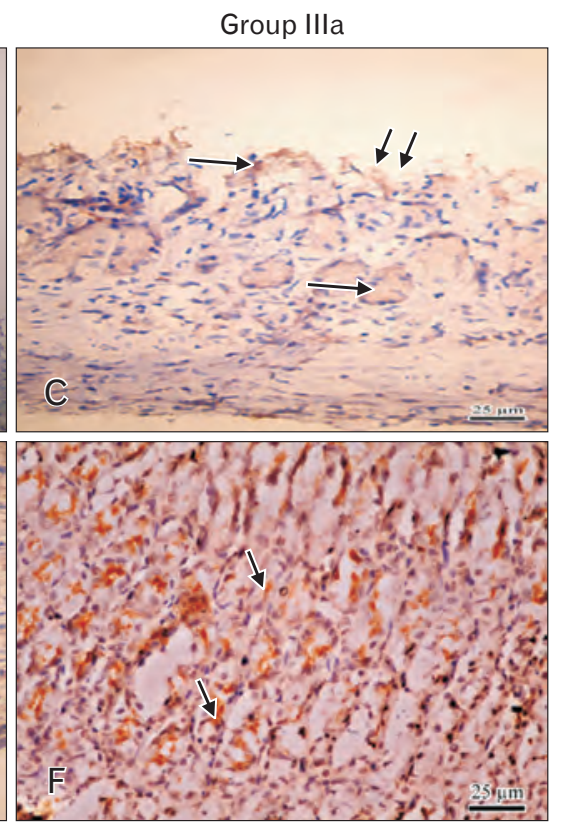

Group IVb

Fig. 4. Immunostained section for vascular endothelial growth factors (VEGF) antibody expression shows Group I (A), the expression in the epithelium and the lamina propria (arrows), inset (arrow head); Group II (B), weak VEGF antibody expression (arrows) in the ulcer region (double arrow); Group IIIa (C) weak VEGF antibody expression (arrows) in the ulcer region (double arrow); Group IIIb (D), weak VEGF antibody expression (arrows) in ulcer region; Group IVa (E), weak VEGF antibody expression in the ulcer region (double arrow); Group IVb (F), strong VEGF antibody expression (arrows) in the epithelium and lamina propria of the fundic glands. Scale bar for all photomicrographs: $25 \mu \mathrm{m}$.
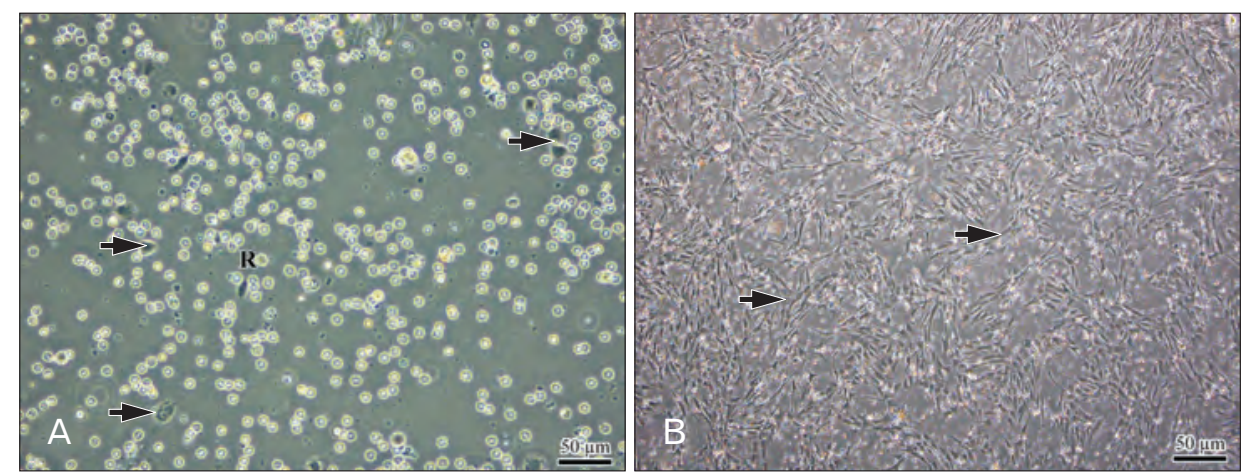

Fig. 5. Photomicrographs of cultured adipose derived mesenchymal stem cells after 24 hours of isolation showing that (A) the cells appear spindle shaped cells (arrowheads) and are accompanied by a large number of red blood cells (R). (B) Cells after 7 days of isolation appear spindle-shaped (arrowheads) with fusiform nuclei and approximately $80 \%$ to $90 \%$ confluence. Scale bar: $50 \mu \mathrm{m}$.

expression of PCNA (Fig. 3C). As regards Group IIIb, the immunostained sections showed weak expression of PCNA (Fig. 3D). While in Group IVa, the immunostained sections showed weak expression of PCNA (Fig. 3E). In Group IVb, the immunostained sections showed strong expression for PCNA (Fig. 3F) in the epithelium and neck region of the fundic glands. Statistical analysis: significant difference from the Group I at $P<0.05$.Significant difference from the Group II at $P<0.05$, histogram 2 (Fig. 3G).

\section{Vascular endothelial growth factor}

The immunostained sections of Group I showed that the VEGF expression was revealed as the dark brown color of the cytoplasm of the epithelial and the endothelial lining cells of blood capillaries of the lamina propria and fundic glands (Fig. 4A). The immune-stained sections showed weak expression in Group II (Fig. 4B), Group IIIa (Fig. 4C), Group IIIb (Fig. 4D), and Group IVa (Fig. 4E). While in Group IVb, the immunostained sections showed strong positive expression in the epithelium and endothelial lining of blood capillaries of the lamina propria (Fig. 4F). 

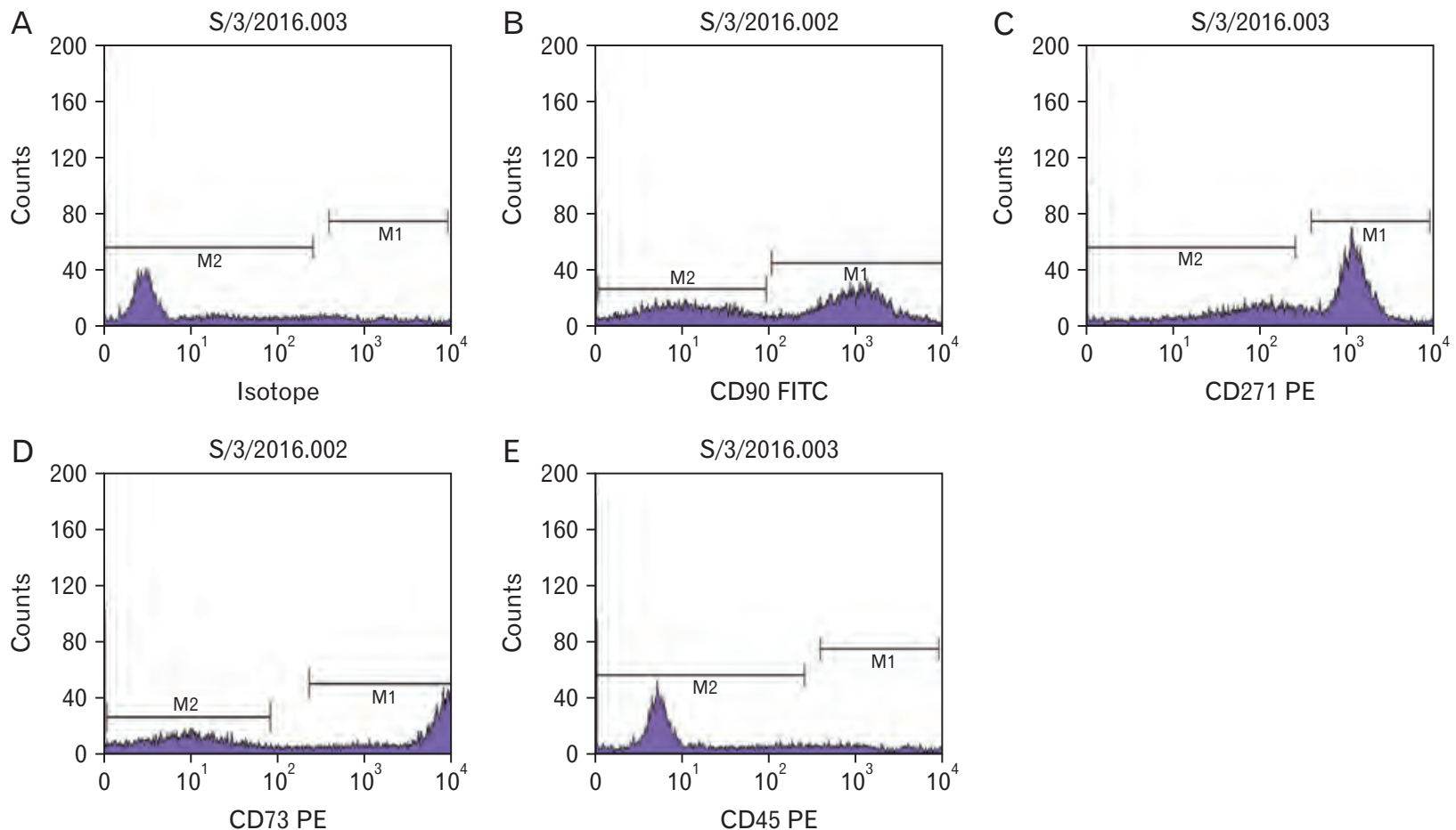

Fig. 6. The flow cytometric analysis of the isolated mesenchymal stem cells (MSCs) showing (A) control group (Isotope); (B): MSCs are positive to CD90 antibody; (C) MSCs are positive to CD271 antibody; (D) MSCs are positive to CD73 antibody; and (E) MSCs are negative to CD45 antibody.
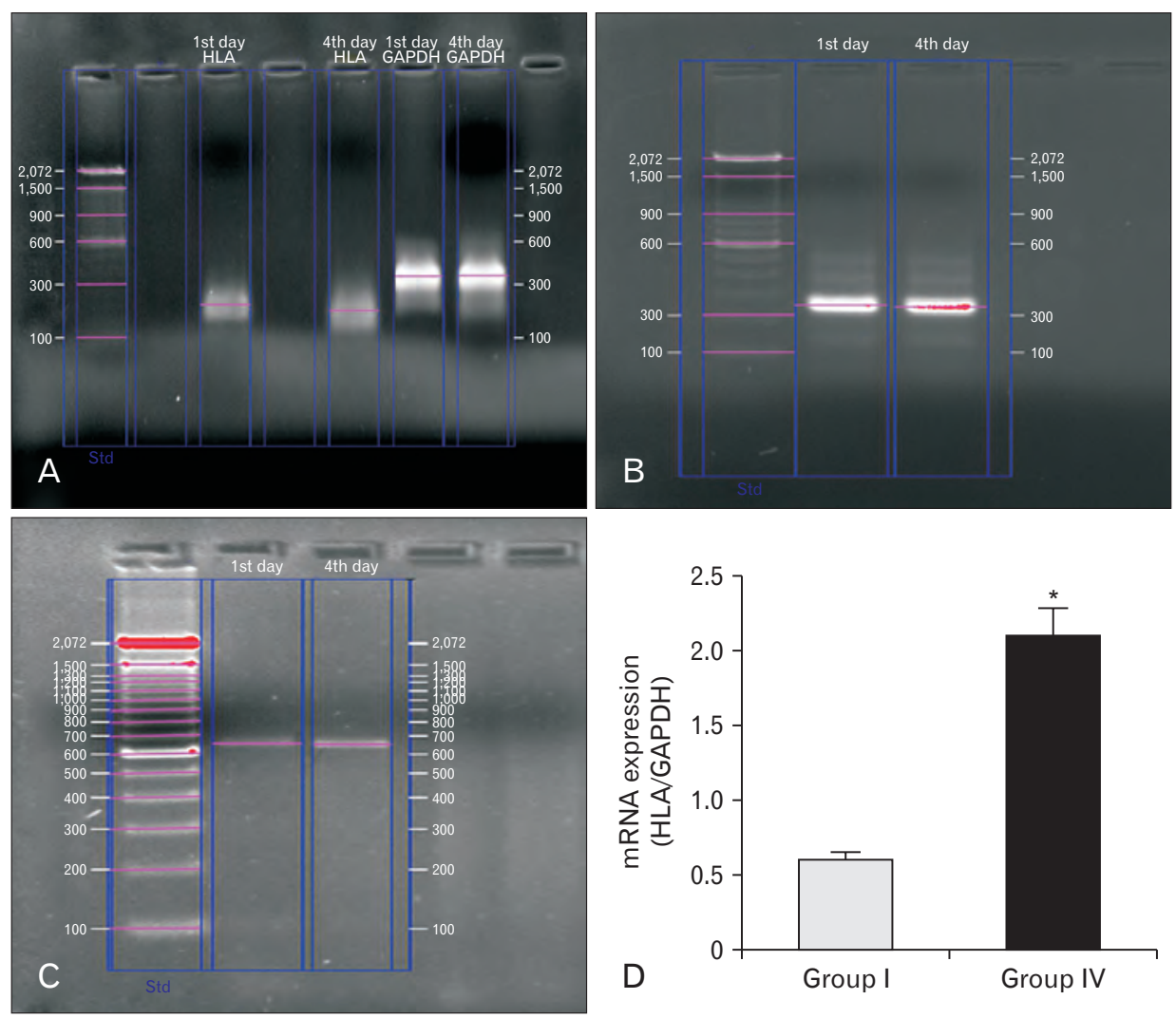

Fig. 7. Images Gel electrophoresis analysis after PCR showing (A) GABDH expression on the 1st and 4th days; human leukocyte antigen (HLA) expression was down regulated in the control group on both the 1st and the 4th days. (B) GABDH expression in the stem cellstreated group on the 1 st 4 th days. (C) HLA expression was upregulated in the Stem cells treated group on the 1st and 4th days. (D) Statistical analysis (histogram 3). *Significant difference of the control group vs. the Stem cells treated group at $P<0.05$. 


\section{Morphology of isolated MSCs}

Examination of the cultured adipose-derived MSCs on the 1st day after isolation showed that while many cells were floating, a few cells were attached. These attached cells were fibroblast-like and appeared spindle shape with vesicular nuclei (Fig. 5A). The cells reached $\sim 80 \%$ confluence on the 7 th day (Fig. 5B).

\section{Characterization of MSCs by flow cytometry}

FACS flow cytometry analysis of isolated MSCs revealed that the cells were negative for CD45 (Fig. 6D), and positive for CD90, CD271, and CD73 (Fig. 6A-C).

\section{Reverse transcription polymerase chain reaction}

Gel electrophoresis performed following conventional PCR showed higher expression of HLA in the Group IV (Fig. 7C) than in the Group I (Fig. 7A). Expression of HLA was normalized to GADPH levels in the two groups (Fig. 7A, B).

\section{Real time PCR results}

The RT-PCR results showed that the expression of HLA gene in the Group IV was higher than that in the Group I. Statistical analysis: Significant difference of the Group I vs. Group IV at $P<0.05$ (Fig. 7D).

\section{Discussion}

Gastric ulceration is a benign lesion on the mucosal epithelium when exposed to excess acid and aggressive pepsin activity [33]. Adipose-derived MSCs represent a very promising line of treatment in many diseases. The use of MSCs is based on their potential capacity to repair damaged tissues and inhibit inflammation and fibrosis [34, 35].

In this study, indomethacin was used for ulcer induction in adult male albino rats. Upon gross examination of stomach tissues, the results of our study showed that administration of indomethacin resulted in multiple hemorrhagic lesions along with a significant increase $(P<0.05)$ in gastric ulcer index in the ulcer group (Group II) when compared with the control group (Group I). This was in agreement with results from previous studies [36, 37]. This is explained by indomethacin comprises polar lipids with a high affinity for the lipophilic areas of cell membranes, where their polar groups trigger membrane disruption, with a loss of structural phospholipids and membrane proteins. This leads in turn to reduce hydrophobicity of the mucosal coat adherent to the mucosal cell surface which facilitates the entry of harmful water-soluble agents and also alter membrane fluidity that plays a key role in the development of the gastric mucosal lesions induced by indomethacin [38]. It was reported that indomethacin possesses much more ability to cause gastric injury than other NSAIDs; as it inhibits both cyclooxygenases (COX-1 and COX-2) which are enzymes responsible for the formation of prostanoids including thromboxane and prostaglandins from arachidonic acid [38, 39]. This will result in suppression of endogenous biosynthesis of prostaglandin with subsequent inhibition of gastro-duodenal bicarbonate secretion; interference with the mucosal barrier and interruption of the mucosal blood flow in animals [24].

The results of our macroscopic examinations in the Group III showed that the number and severity of ulcer differed on successive days following indomethacin administration. On the 1st day, the number of ulcers was higher than the 4th day as indicated by the ulcer index. Also, the rats in this group were found to be in bad general physical condition; four rats in this group died on the 4th day. This may be due to the occurance of complications of healing as infection which delay the healing process. The isolated MSCs have the characteristics of stem cells according to the Mesenchymal and Tissue Stem Cell Committee of the International Society of Cellular Therapy. Results of the macroscopic examination of tissue from the Group IV, showed that the number and severity of ulcers decreased from the 1st to the 4th day as indicated by the ulcer index. Unlike the rats in the Group III, we found that the rats in this group demonstrated normal general condition at the 4th day; this could be due to enhanced healing of the ulcer in Group IV.

Regarding the microscopic results, our study revealed distorted appearance of the fundic mucosa of the Group II, which took the form of desquamated surface epithelium and upper portion of the fundic gland. We also observed submucosal edema marked infiltration with inflammatory cells and congested blood vessels. Separation of cells from one another and loss of the normal architecture of the mucosa were frequently observed. This may be due to a loss of integrity in the intercellular junctions of the surface epithelial and glandular cells. These results are supported by the observations of Werther [40] and Abd-Elmenm et al. [1], who demonstrated that the tight junctions between surface epithelial cells constitute a barrier that prevents back diffusion of acid and pepsin. Additionally, generation of free oxygen radicals and especially lipid peroxide plays a key role in the progression 
of the gastric mucosal lesions caused by indomethacin. The changes observed in the Group II, in this study are due to the permeability disorders of the membranes caused by reactive oxygen species (ROS), which are believed to be responsible for damage to glandular and epithelial cells, which is due to enhancement of water and electrolyte transport into the cells [41-43].

The microscopic results in the Group III showed several different histological features that appeared on the 1st day, including the formation of granulation tissue (fibroblasts and blood capillaries). In addition, normal architecture in the fundic mucosa was lost and cellular infiltration occurred in both the mucosa and submucosa. These conditions continued until the 4th day without significant change. Giant cells were found that could indicate heavy debris accumulation resulting from a severe inflammatory process. All these findings could be due to bad healing process. The formation of granulation tissue observed in the Group III could be due to angiogenesis, which is a feature of ulcer healing. One of the angiogenic growth factors that stimulate the process of angiogenesis is VEGF [44], a naturally secreted glycoprotein that acts as growth factor for endothelial cells and it is produced by several tissues when oxygen tension is decreased [45].

The microscopic examination of the Group IV revealed that the ulcer healing started on the 1st day in the form of granulation tissue formation, disorganized architecture of the fundic mucosa and cellular infiltration. By the 4th day, we found that cellular infiltration, edema and granulation tissue had decreased, which indicate improved healing of the ulcer. This could be explained by that MSCs produce a range of factors implicated in immune modulating effects, such as indoleamine 2,3-dioxygenase, IL-6, IL-10, PGE2, transforming growth factor- $\beta 1$, nitric oxide, heme oxygenase- 1 , and HLA-G5 [46]. They also suppress NK cells, induce polymorphonuclear cell and cytotoxic $\mathrm{T}$ cell apoptosis, and promote the generation of regulatory $\mathrm{T}$ cells [47]. In short, they inhibit innate immunity by blocking the differentiation and maturation of monocytes to dendritic cells, inhibiting NK cells, and inducing neutrophil apoptosis [48].

In addition, regeneration of the surface epithelium and glandular cells in the mucous neck cells, chief cells and parietal cells was observed on the 4th day. This could be due to ability of MSCs to repair tissues, stimulate angiogenesis and prevent fibrosis through their multilineage differentiation capacity. However, recent reports have demonstrated that most of the biological effects of MSCs are mediated by paracrine mechanisms involving the secretion of cytokines, chemokines, and growth factors $[49,50]$. In addition, the biological effects of MSC also may be exerted by the induction and stimulation of endogenous host progenitor cells which improves the regenerative process [51]. In the results of our study, we noticed a decreased incidence of inflammation as cellular infiltration, edema and destructed cells in Group IV, which could be due to the anti-inflammatory effect of MSCs. Recent studies have posited that MSCs may have either an anti-inflammatory or a pro-inflammatory role, depending upon their interaction with other cell types and/or soluble factors [52, 53].

Our results showed that PCNA-positive cells expression in the Group III were weak, with no obvious difference in the results between the 1st and 4th day. In the Group IV, we noticed strong expression observed in the on the 4 th day. We also noticed reepithelization of the tissue surrounding the ulcer which is normally occurring feature of healing process. Our morphometric results showed that PCNA-positive cell expression which indicates a greater proliferation of cells during healing process was statistically higher in the Group IV than in the Group III. The distribution of PCNA-positive cells within the gastric mucosa occurred specifically in the neck region of the fundic glands where the stem regenerating cells are found. Proliferation was also detected at the ulcer margin due to proliferation of the surrounding tissue to replace damaged cells in the ulcer. These could be due to the ability of MSCs to induce proliferation of cells at the ulcer base and at the margin to replace a variety of damaged cells. It has been reported that the MSCs induce cell proliferation by secreting growth factors such as hepatocyte growth factor (HGF) [54] and epidermal growth factor (EGF) [3], both of which are mandatory for cell proliferation. HGF is a potent stimulus for cell proliferation in the gastric epithelium. As an established factor, it may be involved in angiogenesis during ulcer healing [54, 55]. It has been found that MSC administration stimulates liver regeneration in normal mice, and restores this response in obese mice after partial hepatectomy. The therapeutic effects were related to an in vivo stimulation of hepatocyte proliferation as indicated by the expression of PCNA [56].

In addition, hippocampus cell proliferation and neurological function was markedly enhanced in a previous study, this underscore MSCs' potential to promote cellular proliferation by accelerating the expression of PCNA after ischemia/ reperfusion injury [57]. Other investigators reported that ac- 
celeration in the production of HGF by the MSCs in the early period through paracrine effects, supporting the effective treatment strategy in liver regeneration [58].

In our results, we found that VEGF expression in the Group III was weak, with no obvious difference in the results between the 1st and 4th day. This could be due to insufficient amount of secreted VEGF due to the underlying defects in the healing process as infection or fibrosis which can hinder secretion of angiogenic growth factor and hence the angiogenesis. The results from the Group IV revealed strong expression of the antibody in the cytoplasm of the endothelial cells in the lamina propria of the fundic mucosa. We found no obvious difference in VEGF expression on the 1st day. A clear difference was detected on the 4th day on which the expression of the antibody was strong positive. No obvious difference was observed in VEGF expression on the 1st day between the Group III and the Group IV. This could be explained by the ability of the MSCs to secret more VEGF in the ulcer area or it might stimulates the cells which secret VEGF to increase its secretion.

Our flow cytometry results showed that MSCs are adherent, highly proliferating non-hematopoietic cells that express the surface markers CD90, CD217, and CD73, and do not express CD34 and CD45 as demonstrated by flow cytometry analysis, these results were in agreement with those analyses $[54,59]$.

RT-PCR studies revealed that while the HLA-gene was over expressed in the Group IV on 1st and the 4th days, it was expressed in very low levels in the control animals on both days. This means that it was increased (up regulated) in the Group IV compared to the Group I which is with the homing theory. This provides evidence that the enhancement of ulcer healing has been due to injected Stem cells and also reveals that MSCs remain viable during the process of ulcer healing. Also, HLA-up regulation on the 4th day after stem cell injection demonstrated that the cell were in place and still viable at this time allowing them to contribute to the healing process. Statistical analysis, revealed no significant difference in HLA gene expression between the numbers of MSCs that migrated on the 1st day and those that migrated on the 4th day. This could be because the severe inflammatory process that occurred after ulcer induction was still present at the 1st day, and caused the MSCs to migrate to the site of inflammation. On the 4th day, the MSCs were found at the site of the ulcer in nearly the same number which indicates that MSCs were viable and continued to secrete the growth factors that accelerated the healing process. There was a statistically significant difference between the Group IV and Group I.

Resident MSCs movement seems to be directed by cytokines and/or chemokines that become upregulated under conditions of inflammation with subsequent release of MSCs into the circulation and down-regulation of the adhesion molecules that retain MSCs in their niche [58]. The chemokines CXCL9, CXCL16, CCL20, and CCL25 significantly enhanced migration of MSCs across the endothelial cells. It was also found that following adhesion and trans endothelial migration of MSCs, gene expression was altered(disturbed) and chemokine receptors (CXCR3, CXCR6, CCR6, and CCR9) were down-regulated (knocked down) [60].

From the above-mentioned findings, we conclude that adipose-derived MSCs accelerate healing of gastric ulcer in rats. They accelerate cell proliferation to repair the damage caused by the ulcer and enhance angiogenesis which keeps the site of ulcer well oxygenated. This guard against infection which results in defective and complicated of wound healing as fibrosis and the development of chronic gastric ulcers.

\section{ORCID}

Safaa A. Hassan:

https://orcid.org/0000-0002-2902-3228

Amal Taha Abou Elghait:

https://orcid.org/0000-0002-5173-6320

Zainab S. Abdelqader:

https://orcid.org/0000-0003-3275-7780

Fatma Y. Meligy:

https://orcid.org/0000-0002-6372-8731

\section{Author Contributions}

Conceptualization: SAH, ATAE, ZSA, FYM. Data acquisition: SAH, ATAE, ZSA, FYM. Data analysis or interpretation: SAH, ATAE, ZSA, FYM. Drafting of the manuscript: SAH, ATAE, ZSA, FYM. Critical revision of the manuscript: SAH, ATAE, ZSA, FYM. Approval of the final version of the manuscript: all authors.

\section{Conflicts of Interest}

No potential conflict of interest relevant to this article was reported. 


\section{Acknowledgements}

We acknowledge the members of Tissue culture and molecular biology research center, Assiut University, Assiut, Egypt for their valuable support.

\section{References}

1. Abd-Elmenm S, Greish S, Atwa M, Fathelbab M. Evaluation of the role of adipose-derived stem cells in the healing of indomethacin-induced gastric ulceration in rats. J Cell Sci Ther 2016;7:246.

2. Chaturvedi A, Kumar MM, Bhawani G, Chaturvedi H, Kumar M, Goel RK. Effect of ethanolic extract of Eugenia jambolana seeds on gastric ulceration and secretion in rats. Indian J Physiol Pharmacol 2007;51:131-40.

3. Chang Q, Yan L, Wang CZ, Zhang WH, Hu YZ, Wu BY. In vivo transplantation of bone marrow mesenchymal stem cells accelerates repair of injured gastric mucosa in rats. Chin Med J (Engl) 2012;125:1169-74.

4. Jones MK, Wang H, Peskar BM, Levin E, Itani RM, Sarfeh IJ, Tarnawski AS. Inhibition of angiogenesis by nonsteroidal antiinflammatory drugs: insight into mechanisms and implications for cancer growth and ulcer healing. Nat Med 1999;5:1418-23.

5. Najm WI. Peptic ulcer disease. Prim Care 2011;38:383-94, vii.

6. Sonnenberg A. Geographic and temporal variations in the occurrence of peptic ulcer disease. Scand J Gastroenterol Suppl 1985;110:11-24.

7. Badhani S, Jasrotia N, Sharma I, Parashar B, Gupta R. A review on some Indian medicinal plants for antiulcer activity. J Sci Res Pharm 2012;1:6-9.

8. Abraham NS, El-Serag HB, Johnson ML, Hartman C, Richardson P, Ray WA, Smalley W. National adherence to evidencebased guidelines for the prescription of nonsteroidal antiinflammatory drugs. Gastroenterology 2005;129:1171-8.

9. Atuma C, Strugala V, Allen A, Holm L. The adherent gastrointestinal mucus gel layer: thickness and physical state in vivo. Am J Physiol Gastrointest Liver Physiol 2001;280:G922-9.

10. Lichtenberger LM. Gastroduodenal mucosal defense. Curr Opin Gastroenterol 1999;15:463-72.

11. Modlin IM, Kidd M, Lye KD, Wright NA. Gastric stem cells: an update. Keio J Med 2003;52:134-7.

12. Yang H, Ara A, Magilnick N, Xia M, Ramani K, Chen H, Lee TD, Mato JM, Lu SC. Expression pattern, regulation, and functions of methionine adenosyltransferase 2 beta splicing variants in hepatoma cells. Gastroenterology 2008;134:281-91.

13. Ham M, Kaunitz JD. Gastroduodenal defense. Curr Opin Gastroenterol 2007;23:607-16.

14. Chatzaki E, Lambropoulou M, Constantinidis TC, Papadopoulos N, Taché Y, Minopoulos G, Grigoriadis DE. Corticotropinreleasing factor (CRF) receptor type 2 in the human stomach: protective biological role by inhibition of apoptosis. J Cell Physiol 2006;209:905-11.
15. Baatar D, Kawanaka H, Szabo I, Pai R, Jones M, Kitano S, Tarnawski AS. Esophageal ulceration activates keratinocyte growth factor and its receptor in rats: implications for ulcer healing. Gastroenterology 2002;122:458-68.

16. Vanwijck R. [Surgical biology of wound healing]. Bull Mem Acad R Med Belg 2001;156:175-84; discussion 185. French.

17. Tuch BE. Stem cells--a clinical update. Aust Fam Physician 2006;35:719-21.

18. Sibov TT, Severino P, Marti LC, Pavon LF, Oliveira DM, Tobo PR, Campos AH, Paes AT, Amaro E Jr, F Gamarra L, MoreiraFilho CA. Mesenchymal stem cells from umbilical cord blood: parameters for isolation, characterization and adipogenic differentiation. Cytotechnology 2012;64:511-21.

19. Rafei M, Birman E, Forner K, Galipeau J. Allogeneic mesenchymal stem cells for treatment of experimental autoimmune encephalomyelitis. Mol Ther 2009;17:1799-803.

20. González MA, Gonzalez-Rey E, Rico L, Büscher D, Delgado M. Adipose-derived mesenchymal stem cells alleviate experimental colitis by inhibiting inflammatory and autoimmune responses. Gastroenterology 2009;136:978-89.

21. Bai L, Lennon DP, Caplan AI, DeChant A, Hecker J, Kranso J, Zaremba A, Miller RH. Hepatocyte growth factor mediates mesenchymal stem cell-induced recovery in multiple sclerosis models. Nat Neurosci 2012;15:862-70.

22. Ren G, Zhang L, Zhao X, Xu G, Zhang Y, Roberts AI, Zhao RC, Shi Y. Mesenchymal stem cell-mediated immunosuppression occurs via concerted action of chemokines and nitric oxide. Cell Stem Cell 2008;2:141-50.

23. Francis MP, Sachs PC, Elmore LW, Holt SE. Isolating adiposederived mesenchymal stem cells from lipoaspirate blood and saline fraction. Organogenesis 2010;6:11-4.

24. Thong-Ngam D, Choochuai S, Patumraj S, Chayanupatkul M, Klaikeaw N. Curcumin prevents indomethacin-induced gastropathy in rats. World J Gastroenterol 2012;18:1479-84.

25. Ali S, ElGibaly R, Abdel-Maksoud S. Effect of Musa sapientum (Banana) on indomethacin-induced gastric mucosal injury in rats: histological study. J Med Histol 2018;2:11-28.

26. Choi HS, Kim HJ, Oh JH, Park HG, Ra JC, Chang KA, Suh YH. Therapeutic potentials of human adipose-derived stem cells on the mouse model of Parkinson's disease. Neurobiol Aging 2015;36:2885-92.

27. Zickri MB, Fadl SG, Metwally HG. Comparative study between intravenous and intraperitoneal stem cell therapy in amiodarone induced lung injury in rat. Int J Stem Cells 2014;7:1-11.

28. Kunchandy J, Khanna S, Kulkarni SK. Effect of alpha2 agonists clonidine, guanfacine and B-HT 920 on gastric acid secretion and ulcers in rats. Arch Int Pharmacodyn Ther 1985;275:12338 .

29. Bancroft JD, Gamble M. Theory and practice of histological techniques. 6th ed. Philadelphia: Churchill Livingstone Elsevier; 2008.

30. Takahashi H, Fujita S, Yamabe S, Moriishi T, Okabe H, Tajima Y, Mizuno A. Comparison of proliferating cell nuclear antigen expression in odontogenic keratocyst and ameloblastoma: an 
immunohistochemical study. Anal Cell Pathol 1998;16:185-92.

31. Jo YY, Lee HJ, Kook SY, Choung HW, Park JY, Chung JH, Choung YH, Kim ES, Yang HC, Choung PH. Isolation and characterization of postnatal stem cells from human dental tissues. Tissue Eng 2007;13:767-73.

32. Fakhry J, Wang J, Martins P, Fothergill LJ, Hunne B, Prieur P, Shulkes A, Rehfeld JF, Callaghan B, Furness JB. Distribution and characterisation of CCK containing enteroendocrine cells of the mouse small and large intestine. Cell Tissue Res 2017;369:245-53.

33. Khazaei M, Salehi H. Protective effect of falcaria vulgaris extract on ethanol induced gastric ulcer in rat. Iran J Pharmacol Ther 2006;5:43-6.

34. Nauta AJ, Fibbe WE. Immunomodulatory properties of mesenchymal stromal cells. Blood 2007;110:3499-506.

35. Satija NK, Singh VK, Verma YK, Gupta P, Sharma S, Afrin F, Sharma M, Sharma P, Tripathi RP, Gurudutta GU. Mesenchymal stem cell-based therapy: a new paradigm in regenerative medicine. J Cell Mol Med 2009;13:4385-402.

36. Inas Z, Hala A, Gehan H. Gastroprotective effect of Cordia myxa L. fruit extract against indomethacin-induced gastric ulceration in rats. Life Sci J 2011;8:433-45.

37. Abbas AM, Sakr HF. Effect of selenium and grape seed extract on indomethacin-induced gastric ulcers in rats. J Physiol Biochem 2013;69:527-37.

38. Suleyman H, Albayrak A, Bilici M, Cadirci E, Halici Z. Different mechanisms in formation and prevention of indomethacininduced gastric ulcers. Inflammation 2010;33:224-34.

39. Wallace JL, McKnight W, Reuter BK, Vergnolle N. NSAIDinduced gastric damage in rats: requirement for inhibition of both cyclooxygenase 1 and 2. Gastroenterology 2000;119:70614.

40. Werther JL. The gastric mucosal barrier. Mt Sinai J Med 2000;67:41-53.

41. Seifried HE, Anderson DE, Fisher EI, Milner JA. A review of the interaction among dietary antioxidants and reactive oxygen species. J Nutr Biochem 2007;18:567-79.

42. Al-sagaaf S, Ramadan WS, Abunasef SK. Does commercial aloe vera protects the structure of the gastric mucosa against acute nonsteroidal anti-inflammatory drug (diclofenac sodium)induced damage? Egypt J Histol 2011;34:80-91.

43. El-Mehi AE, El-Sherif NM. Influence of acrylamide on the gastric mucosa of adult albino rats and the possible protective role of rosemary. Tissue Cell 2015;47:273-83.

44. Connolly DT. Vascular permeability factor: a unique regulator of blood vessel function. J Cell Biochem 1991;47:219-23.

45. Razban V, Lotfi AS, Soleimani M, Ahmadi H, Massumi M, Khajeh S, Ghaedi M, Arjmand S, Najavand S, Khoshdel A. HIF$1 \alpha$ overexpression induces angiogenesis in mesenchymal stem cells. Biores Open Access 2012;1:174-83.

46. Thomson AW, Turnquist HR, Raimondi G. Immunoregulatory functions of mTOR inhibition. Nat Rev Immunol 2009;9:32437.

47. Devine SM, Bartholomew AM, Mahmud N, Nelson M, Patil
S, Hardy W, Sturgeon C, Hewett T, Chung T, Stock W, Sher D, Weissman S, Ferrer K, Mosca J, Deans R, Moseley A, Hoffman R. Mesenchymal stem cells are capable of homing to the bone marrow of non-human primates following systemic infusion. Exp Hematol 2001;29:244-55.

48. Bernardo ME, Zaffaroni N, Novara F, Cometa AM, Avanzini MA, Moretta A, Montagna D, Maccario R, Villa R, Daidone MG, Zuffardi O, Locatelli F. Human bone marrow derived mesenchymal stem cells do not undergo transformation after long-term in vitro culture and do not exhibit telomere maintenance mechanisms. Cancer Res 2007;67:9142-9.

49. Binato R, de Souza Fernandez T, Lazzarotto-Silva C, Du Rocher B, Mencalha A, Pizzatti L, Bouzas LF, Abdelhay E. Stability of human mesenchymal stem cells during in vitro culture: considerations for cell therapy. Cell Prolif 2013;46:10-22.

50. Teixeira FG, Salgado AJ. Mesenchymal stem cells secretome: current trends and future challenges. Neural Regen Res 2020;15:75-7.

51. Toma C, Pittenger MF, Cahill KS, Byrne BJ, Kessler PD. Human mesenchymal stem cells differentiate to a cardiomyocyte phenotype in the adult murine heart. Circulation 2002;105:938.

52. Fan H, Zhao G, Liu L, Liu F, Gong W, Liu X, Yang L, Wang J, Hou Y. Pre-treatment with IL-1 $\beta$ enhances the efficacy of MSC transplantation in DSS-induced colitis. Cell Mol Immunol 2012;9:473-81.

53. Danese S, Rutella S, Vetrano S. Mesenchymal stromal cells in inflammatory bowel disease: conspirators within the 'colitogenic niche'? Gut 2013;62:1098-9.

54. Hayashi Y, Tsuji S, Tsujii M, Nishida T, Ishii S, Iijima H, Nakamura T, Eguchi H, Miyoshi E, Hayashi N, Kawano S. Topical transplantation of mesenchymal stem cells accelerates gastric ulcer healing in rats. Am J Physiol Gastrointest Liver Physiol 2008;294:G778-86.

55. Matsumoto K, Nakamura T. Hepatocyte growth factor (HGF) as a tissue organizer for organogenesis and regeneration. Biochem Biophys Res Commun 1997;239:639-44.

56. Ezquer F, Bahamonde J, Huang YL, Ezquer M. Administration of multipotent mesenchymal stromal cells restores liver regeneration and improves liver function in obese mice with hepatic steatosis after partial hepatectomy. Stem Cell Res Ther 2017;8:20.

57. Jiang H, Qu L, Dou R, Lu L, Bian S, Zhu W. Potential role of mesenchymal stem cells in alleviating intestinal ischemia/reperfusion impairment. PLoS One 2013;8:e74468.

58. Liu ZJ, Zhuge Y, Velazquez OC. Trafficking and differentiation of mesenchymal stem cells. J Cell Biochem 2009;106:984-91.

59. Meligy FY, Shigemura K, Behnsawy HM, Fujisawa M, Kawabata $\mathrm{M}$, Shirakawa $\mathrm{T}$. The efficiency of in vitro isolation and myogenic differentiation of MSCs derived from adipose connective tissue, bone marrow, and skeletal muscle tissue. In Vitro Cell Dev Biol Anim 2012;48:203-15.

60. Kallmeyer K, Pepper MS. Homing properties of mesenchymal stromal cells. Expert Opin Biol Ther 2015;15:477-9. 